\title{
Sébastien Castellion, Dialogues sacrés - Dialogi sacri (Premier Livre)
}

\section{Michele Mastroianni}

\section{Q OpenEdition}

1 Journals

\section{Edizione digitale}

URL: http://journals.openedition.org/studifrancesi/32963

DOI: 10.4000/studifrancesi.32963

ISSN: 2421-5856

\section{Editore}

Rosenberg \& Sellier

\section{Edizione cartacea}

Data di pubblicazione: 1 décembre 2005

Paginazione: 625

ISSN: 0039-2944

\section{Notizia bibliografica digitale}

Michele Mastroianni, «Sébastien Castellion, Dialogues sacrés - Dialogi sacri (Premier Livre)», Studi Francesi [Online], 147 (XLX | III) | 2005, online dal 30 novembre 2015, consultato il 20 avril 2021. URL: http://journals.openedition.org/studifrancesi/32963; DOI: https://doi.org/10.4000/studifrancesi. 32963

Questo documento è stato generato automaticamente il 20 avril 2021.

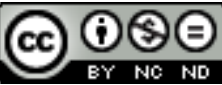

Studi Francesi è distribuita con Licenza Creative Commons Attribuzione - Non commerciale - Non opere derivate 4.0 Internazionale. 


\title{
Sébastien Castellion, Dialogues sacrés - Dialogi sacri (Premier Livre)
}

\author{
Michele Mastroianni
}

\section{NOTIZIA}

SÉBASTIEN CASTELLION, Dialogues sacrés - Dialogi sacri (Premier Livre), édition critique par DAVID AMHERDT et YVES GIRAUD, Genève, Droz («Textes Littéraires Français», 571), pp. 264.

1 Tra la fine del Quattrocento e la prima metà del Cinquecento compaiono in Europa numerosi dialoghi bilingui (in latino e in volgare) a destinazione scolastica per fare apprendere con un metodo diretto - e nello stesso tempo su contenuti edificanti, dal punto di vista morale o religioso - la lingua latina ai ragazzi. In questo genere di produzione si cimentarono umanisti illustri come Erasmo e Vivès. Anche Sébastien Castellion compose a tal fine i suoi Dialogi sacri (1543), accompagnati da una traduzione francese, quando era régent del collegio ginevrino di Rive. Nella prefazione dedicata a Mathurin Cordier, anch'esso autore di dialoghi a destinazione similare, Castellion dichiara di non avere scelto come materiale e tematica le commedie di Terenzio (spesso sfruttate a questo fine didattico) per timori d'ordine morale, e di avere ritenuto più edificante scegliere la Bibbia per argomento. Egli afferma infatti: «His ego de causis familiaria quaedam et iucunda colloquia de Hebraeorum libris excerpseram et in latinum sermonem converteram, quibus discipulorum nostrorum et linguas latinitate et animos bonis moribus eadem opera informaremus» (pp. 46-47). L'autore classico che avrebbe potuto fornire un modello per eccellenza, Cicerone, è considerato troppo difficile da Castellion, che compone egli stesso dei dialoghi semplici che teatralizzano, per così dire, episodi dell'Antico (i primi tre libri) e del Nuovo Testamento (il quarto libro). Nel primo libro, qui edito criticamente, abbiamo 32 dialoghi tratti dalla Genesi, dall'Esodo, dai Numeri, dai Giudici e da Rut. L'introduzione comprende otto capitoli. Nel primo vengono presentate la vita e l'opera di Castellion; nel secondo si affronta il problema dell'insegnamento del latino a livello elementare, nell'Umanesimo, e di quello strumento pedagogico che sono i dialoghi, utilizzati all'epoca per l'insegnamento della 
lingua classica; nel terzo vengono presentati i Dialoghi di Castellion e viene illustrato il suo metodo; nel quarto viene offerto un breve panorama della storia editoriale dei Dialogi; nel quinto si analizza il latino dei Dialogi, mentre il sesto è consacrato al testo francese; nel settimo e ottavo capitolo vengono illustrati i principi seguiti per l'edizione del testo e per la stesura della note. Conclude il lavoro un'interessante appendice grammaticale, un glossario per il testo francese e una bibliografia esauriente. 